VALENTE, T.N.P. Utilização de resíduos de frutas na alimentação de ruminantes. PUBVET, Londrina, V. 5, N. 15, Ed. 162, Art. 1099, 2011.

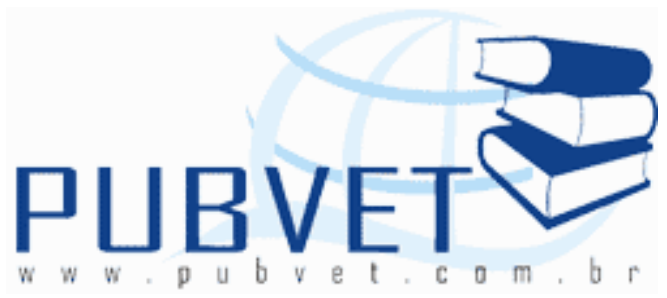

PUBVET, Publicações em Medicina Veterinária e Zootecnia.

\title{
Utilização de resíduos de frutas na alimentação de ruminantes
}

\section{Tiago Neves Pereira Valente ${ }^{1}$}

${ }^{1}$ Zootecnista - Doutor em Nutrição de Ruminantes pela Universidade Federal de Viçosa (UFV), Pós-Doutorando na Universidade Estadual do Norte Fluminense (UENF) - bolsista PNPD-CAPES. E-mail: tiagozootecnista@yahoo.com.br

\section{Resumo}

A Região Nordeste do Brasil apresenta grande importância no cultivo da maioria das espécies frutíferas tropicais, tendo destaque o abacaxi, caju, mamão, manga, maracujá. Nesta região vem se desenvolvendo um importante setor da agropecuária. Em resposta a esse avanço, o número de agroindústrias instaladas por toda a região tem aumentado significativamente, gerando um incremento na produção de resíduos agroindustriais não utilizáveis na alimentação humana, que podem ser aproveitados na dieta animal, tornado-se importante fator de barateamento nos custos de produção.

Palavras-chave: consumo, digestibilidade, subprodutos 
VALENTE, T.N.P. Utilização de resíduos de frutas na alimentação de ruminantes. PUBVET, Londrina, V. 5, N. 15, Ed. 162, Art. 1099, 2011.

\title{
Use of residues of fruits in the feeding of ruminants
}

\begin{abstract}
The Brazil Northeast Region presents great importance in the culture of the majority of the tropical fruitful species, having has detached the pineapple, cashew, papaya, sleeve, and passion fruit. In this region it comes if developing an important sector of the farming. In response to this advance, the number of agribusiness installed for all the region has increased significantly, generating an increment in the production of not utility agronomy residues in the feeding human, that can be used to advantage in the animal diet, become important factor of reduction in price in the production costs.
\end{abstract}

Keywords: byproducts, digestibility, intake

\section{Introdução}

O subproduto do processamento de frutas é variável dependente do objetivo da indústria processadora. Estes resíduos podem ser usados no enriquecimento de silagens como também diretamente no cocho dos animais. Na região Nordeste onde existe grande disponibilidade de subprodutos e também a região com maior quantidade de experimentos realizados com ruminantes normalmente da espécie ovina. Surge então a necessidade de se estudar a viabilidade de incluir diversas fontes alimentares alternativas e quantificar as respostas animais em termos produtivos e econômicos. Uma das alternativas é a introdução dos subprodutos agroindustriais na dieta dos animais; porém, a maioria desses alimentos ainda não foi estudada quanto à sua composição e seus níveis adequados de utilização econômica e biológica na produção animal (LOUSADA JúNIOR et al., 2006). 
VALENTE, T.N.P. Utilização de resíduos de frutas na alimentação de ruminantes. PUBVET, Londrina, V. 5, N. 15, Ed. 162, Art. 1099, 2011.

\section{Abacaxi}

O Brasil como país tropical é um dos três maiores produtores mundiais de abacaxi e a industrialização do abacaxi para processamento de suco e conservas, gera uma grande quantidade de resíduos como frutos descartados, casca, miolo e coroa que podem ser utilizados para alimentação de ruminantes (FRANZOLIN \& SOARES 2005). Existem variações na composição química e valor nutritivo dos resíduos da planta e daqueles produzidos pelas indústrias de conserva. A utilização de resíduos agrícolas e agroindustriais na alimentação de ruminantes visando contornar problemas de escassez de forragem durante as épocas críticas e reduzir os custos com alimentação animal tem sido uma preocupação constante dos nutricionistas. O resíduo de abacaxi, composto de cascas e bagaço do fruto, proveniente de uma indústria de beneficiamento, com teores de matéria seca $(M S)=87,87 \%$; matéria orgânica $(M O)=89,92 \%$; matéria mineral $(M M)=$ $10,08 \%$; proteína bruta $(\mathrm{PB})=7,37 \%$; fibra em detergente neutro (FDN) = $72,12 \%$; fibra em detergente ácido $(\mathrm{FDA})=33,72 \%$; celulose $(\mathrm{CEL})=24,0 \%$; lignina $(\mathrm{LIG})=6,11 \%$; energia metabolizável EM (Mcal/kg) = 2,09 (Correia, et al. 2006). Um experimento foi feito para avaliar a possibilidade de utilização de resíduos de abacaxi na alimentação de caprinos em crescimento, com níveis de substituição do feno de coastcross por este resíduo de abacaxi em até 100 , ou seja, perfazendo 37\% da dieta total. Correia, et al. 2006, perceberam maiores coeficientes de digestibilidade da MO, FDA e CEL $(P<0,05)$, enquanto, para MS e FDN, observou-se comportamento inverso. Podendo ser de $100 \%$ o nível de inclusão de resíduo de abacaxi promoveu ganho de peso satisfatório, de modo que o nível $100 \%$ de substituição permitiu que os caprinos tivessem uma conversão alimentar de 5,6, e também foi percebido melhora os coeficientes de digestibilidade da matéria orgânica, da fibra em detergente ácido e da celulose das rações. 
VALENTE, T.N.P. Utilização de resíduos de frutas na alimentação de ruminantes. PUBVET, Londrina, V. 5, N. 15, Ed. 162, Art. 1099, 2011.

Prado et al. (2003) avaliaram diferentes níveis de substituição da silagem de milho pela silagem de resíduo industrial de abacaxi em até $60 \%$, perceberam redução no consumo de MS e MO à medida que aumentava a substituição pelo resíduo de abacaxi. Mas, ao avaliarem o desempenho e características de carcaça em bovinos confinados, não observaram diferenças entre os tratamentos, concluindo que a silagem de resíduos de abacaxi é viável para uso em animais em terminação, porém, apresenta elevado teor de água. Fato também verificado por Lallo et al. (2003) estes autores também ressaltaram que a silagem de resíduo de abacaxi é rico em pectina com boa capacidade fermentativa pelos microrganismos no rúmen. Lallo et al. (2003) ao avaliarem degradabilidade ruminal em bovinos de corte encontrou valores de $28,8 \% ; 49,4 \%$ e 4,2\%/h para os parâmetros a, b e c da MS e 55,9\%; 34,6\% e 5,5\%/h para PB. E valores de 51,4 e 74,1\%, respectivamente para degradabilidade efetiva da MS e PB para a taxa de passagem estimada em $5 \% / \mathrm{h}$.

\section{Goiaba}

O Brasil é um dos maiores produtores de goiaba do mundo sendo que os estados de Pernambuco, Paraíba e São Paulo se destacam no cenário nacional.

Ao trabalharem com diferentes níveis de inclusão de resíduo de goiaba em até 20\% na silagem de capim-elefante Gonçalves et al., 2004 perceberam a eficiência em termos de elevação nos teores de MS das silagens. Mas, verificaram reduzidos efeitos sobre as características químicas das silagens. No nível de adição de $15 \%$ de subproduto da goiaba a silagem alcançou a faixa ideal de MS (30-35\%) indicada para a ocorrência de um bom processo fermentativo. Para cada $1 \%$ de adição do subproduto da goiaba, o teor de MS das silagens se elevou em 0,50 pontos percentuais.

O nível mínimo de 7\% de PB não foi alcançado em nenhum nível de adição de subproduto da goiaba às silagens. Entendendo que a silagem de capim- 
VALENTE, T.N.P. Utilização de resíduos de frutas na alimentação de ruminantes. PUBVET, Londrina, V. 5, N. 15, Ed. 162, Art. 1099, 2011.

elefante tinha 4,5\% de PB e o resíduo de goiaba 7,8\% de PB. Em todos os níveis de adição dos subprodutos, as silagens se mantiveram dentro da faixa ideal de pH considerada para silagens bem conservadas $(4,1-4,2)$ tabela1 e 2 .

Tabela 1 - Teores de Matéria Seca (MS), Proteína Bruta (PB), Fibra em Detergente Neutro (FDN), Fibra em Detergente Ácido (FDA) e Hemicelulose (HC) dos subprodutos da goiaba e do capim elefante utilizado na ensilagem

\begin{tabular}{llllll}
\hline Materiais & MS (\%) & PB (\%) & FDN (\%) & FDA (\%) & HC (\%) \\
\hline Goiaba & 88,80 & 7,80 & 72,60 & 54,80 & 17,80 \\
Silagem capim elefante & 23,20 & 4,50 & 76,10 & 45,20 & 30,80 \\
\hline
\end{tabular}

Gonçalves et al., 2004

LOUSADA JÚNIOR et al., (2007) encontraram valores de 32,20\% de DIVMS sendo a pior digestibilidade entre cinco resíduos de frutas estudados. E AZEVÊDO et al. (2007a) também perceberam pior resultado para goiaba com coeficiente de digestibilidade aparente da MS de 52,57\%.

Tabela 2 - Teores de Matéria Seca (MS), Proteína Bruta (PB), Fibra em Detergente Neutro (FDN), Fibra em Detergente Ácido (FDA), Hemicelulose $(\mathrm{HC})$, valores de $\mathrm{pH}$ das silagens de capim elefante contendo diferentes níveis de subproduto do processamento da goiaba

\begin{tabular}{llllll}
\hline Variáveis & \multicolumn{5}{c}{ Níveis } \\
\cline { 2 - 6 } & $0 \%$ & $5 \%$ & $10 \%$ & $15 \%$ & $20 \%$ \\
\hline Goiaba & 21,90 & 23,90 & 27,10 & 30,30 & 32,70 \\
MS & 4,60 & 5,00 & 5,70 & 5,90 & 6,20 \\
PB & 73,80 & 74,90 & 74,60 & 75,40 & 76,80 \\
FDN & 46,90 & 48,10 & 48,50 & 50,90 & 52,50 \\
FDA & 26,80 & 26,90 & 26,00 & 24,50 & 24,30 \\
HC & 4,10 & 4,20 & 4,20 & 4,10 & 4,20 \\
PH & & &
\end{tabular}

Gonçalves et al., 2004 
VALENTE, T.N.P. Utilização de resíduos de frutas na alimentação de ruminantes. PUBVET, Londrina, V. 5, N. 15, Ed. 162, Art. 1099, 2011.

\section{Caju}

A produção mundial de caju foi de 1,671 milhões de toneladas em 2005 (FAO), e a produção brasileira do fruto foi de 1,603 milhões de toneladas em 2005 no mesmo período sendo que os estados do Ceará e Piauí se destacaram. O bagaço do caju (BC) pode ser utilizado na ensilagem de capim e FERREIRA et al., 2004 trabalharam com níveis crescentes de adição de (BC) com base na matéria natural até o nível de $48 \%$ de inclusão na ensilagem de capim-elefante, sendo que a composição químico-bromatológica do bagaço é $25,4 \% \mathrm{MS}, 14,2 \%$ de PB, $4,1 \%$ de EE e $65,5 \%$ de FDN. FERREIRA et al., (2004) recomenda a adição de até $47,7 \%$ do (BC) para se obter o nível máximo de PB e, aproximadamente, 37,5\% de adição de BC para atingir o menor nível de FDN. DANTAS FILHO et al. (2007), ao trabalharem com polpa de caju desidratada que apresentava em sua composição bromatológica 16,5\% de PB e 62,64\% de FDN, em níveis crescentes de substituição em até $40 \%$ de uma ração concentrada na base de farelo de soja e milho, para ovinos em crescimento recebendo $30 \%$ de feno de Tifton. E concluíram que o nível de $30 \%$ substituição teve o melhor resultado. Porém a digestibilidade foi influenciada pelo nível de inclusão da polpa de caju tabela 3.

Tabela 3. Coeficientes de digestibilidade dos nutrientes em ovinos alimentados com dietas contendo diferentes níveis de polpa de caju

\begin{tabular}{lccccc}
\hline Parâmetro & \multicolumn{5}{c}{ Nível de inclusão de Polpa de caju desidratada (\%) } \\
\cline { 2 - 6 } & 0 & 10 & 20 & 30 & 40 \\
\hline DMS & 72,31 & 70,44 & 67,03 & 61,03 & 56,40 \\
DMO & 74,70 & 72,93 & 69,95 & 64,35 & 59,29 \\
DPB & 69,19 & 65,47 & 55,95 & 54,87 & 45,59 \\
DFDN & 65,76 & 61,58 & 57,70 & 51,72 & 48,31 \\
DFDA & 60,99 & 46,35 & 43,74 & 28,71 & 26,52 \\
\hline
\end{tabular}

DANTAS FILHO et al. 2007

A castanha de caju também pode ser utilizada na alimentação animal quando esta não está em condição para consumo humano. Sua composição 
VALENTE, T.N.P. Utilização de resíduos de frutas na alimentação de ruminantes. PUBVET, Londrina, V. 5, N. 15, Ed. 162, Art. 1099, 2011.

bromatológica é caracterizada por altos valores de extrato etério (EE) em torno de $35,8 \%$ e $22,1 \%$ de PB. RODRIGUES et al., (2003) utilizaram o farelo de castanha de caju (FCC) para ovinos alimentados em uma base de $70 \%$ de forragem e $30 \%$ de concentrado, com substituição de até $36 \%$ de FCC no concentrado. Foram observadas diminuição no Consumo de MS, PB e EE. O consumo de EE elevou-se com a adição FCC às dietas. O ganho de peso e a conversão alimentar foram semelhantes para as quatro dietas fornecidas. Portanto, o FCC deve ser utilizado com um nível de inclusão de $24 \%$ do concentrado, não ultrapassando $6 \%$ de lipídios na dieta total.

\section{Maracujá}

O Brasil é o maior produtor mundial com 317.000 toneladas de frutos e os estados da Bahia, São Paulo e Sergipe juntos representam 50,8\% da produção nacional. Reis et al., (2000) trabalharam com ovinos e analisaram consumo voluntário e digestibilidade aparente de 5 diferentes silagens assim constituídas: $100 \%$ de resíduos de fruto do maracujá; $75 \%$ de resíduos de fruto do maracujá e $25 \%$ de capim- elefante; $50 \%$ de resíduos de fruto de maracujá e $50 \%$ de capimelefante; $25 \%$ de resíduos de fruto do maracujá e $75 \%$ do capim-elefante. De modo que a composição bromatológica está na tabela 4.

Tabela4. Composição bromatológica das silagens de resíduos do fruto de maracujá.

\begin{tabular}{lllll}
\hline Silagens & $\begin{array}{l}\text { MS } \\
(\%)\end{array}$ & $\begin{array}{l}\text { PB } \\
(\%)\end{array}$ & $\begin{array}{l}\text { FDN } \\
(\%)\end{array}$ & $\begin{array}{l}\text { FDA } \\
(\%)\end{array}$ \\
\hline $100 \%$ resíduos & 18,99 & 10,47 & 60,32 & 50,95 \\
$75 \%$ resíduos & 18,54 & 8,52 & 66,90 & 54,09 \\
$50 \%$ resíduos & 21,90 & 6,85 & 71,69 & 54,19 \\
$25 \%$ resíduos & 25,11 & 5,95 & 69,80 & 55,28 \\
$0 \%$ resíduo & 27,44 & 10,11 & 71,41 & 50,43 \\
\hline
\end{tabular}

Reis et al., 2000 
VALENTE, T.N.P. Utilização de resíduos de frutas na alimentação de ruminantes. PUBVET, Londrina, V. 5, N. 15, Ed. 162, Art. 1099, 2011.

O teor de matéria seca aumentou em função dos níveis de capim-elefante presentes nas silagens, sendo maior quando diminuía o resíduo de maracujá. Para PB apenas a silagem com 25\% de resíduos de fruto do maracujá (5,95\%), o nível ficou abaixo de 7\%, mínimo ideal para que não haja decréscimo no consumo voluntário e na digestibilidade da matéria seca. O coeficiente de digestibilidade aparente da matéria seca aumentou com aumento da inclusão do subproduto. Reis et al., (2000) concluíram que as silagens constituídas por 100\% de resíduos de fruto do maracujá não supriram as exigências dos animais, quando avaliou-se o consumo voluntário; portanto, não poderão ser utilizadas como única fonte de volumoso. NEIVA et al. (2006) também trabalharam com adição de subproduto desidratado do maracujá ao capim-elefante no momento da ensilagem e perceberam que houve aumento no valor nutritivo das silagens, podendo ser recomendados níveis de até $14 \%$ deste subprotudo. NEIVA et al. (2006) observaram que os ovinos aumentaram o consumo de MS e PB tabela 5. NEIVA JÚNIOR et al. (2007) utilizaram diferentes aditivos para silagem de resíduo de maracujá, ocorreu diminuição da digestibilidade In vitro da MS que no tratamento testemunha era de 57,58\%. LOUSADA JÚNIOR et al., (2006) encontraram valores de DIVMS de 62,11.

Tabela 5. Consumo de MS, PB, FDN e FDA por ovinos

\begin{tabular}{|c|c|c|c|c|}
\hline & $\begin{array}{l}\text { Consumo } \\
\text { de MS }\end{array}$ & $\begin{array}{l}\text { Consumo de } \\
\text { PB }\end{array}$ & $\begin{array}{l}\text { Consumo } \\
\text { de FDN }\end{array}$ & $\begin{array}{l}\text { Consumo } \\
\text { de FDA }\end{array}$ \\
\hline Silagem & \multicolumn{2}{|c|}{ g/animal/dia } & \multicolumn{2}{|c|}{ (\%PV) } \\
\hline $\begin{array}{l}\text { Capim-elefante }+0 \% \text { resd. } \\
\text { Maracujá } \\
\text { Capim-elefante }+3,5 \%\end{array}$ & 444,6 & 26,6 & 1,8 & 1,1 \\
\hline $\begin{array}{l}\text { resd. Maracujá } \\
\text { Capim-elefante }+7,0 \%\end{array}$ & 525,9 & 36,7 & 1,5 & 1,2 \\
\hline $\begin{array}{l}\text { resd. Maracujá } \\
\text { Capim-elefante }+10,5 \%\end{array}$ & 459,5 & 36,0 & 1,3 & 0,8 \\
\hline $\begin{array}{l}\text { resd. Maracujá } \\
\text { Capim-elefante }+14,0 \%\end{array}$ & 561,1 & 48,8 & 1,7 & 1,1 \\
\hline resd. Maracujá & 793,5 & 66,7 & 2,3 & 1,6 \\
\hline
\end{tabular}

Neiva et al, 2006 
VALENTE, T.N.P. Utilização de resíduos de frutas na alimentação de ruminantes. PUBVET, Londrina, V. 5, N. 15, Ed. 162, Art. 1099, 2011.

\section{Mamão}

O Brasil é o maior produtor mundial de mamão com 1,6 milhões de toneladas (FAO, 2005) e os estados que se destacam são Bahia, Paraíba e Espírito Santo. A composição bromatológica é de 10,07\% de MS, 14,80\% de PB, 7,28\% de EE, 43,46\% de FDN AZEVÊDO et al. (2007b). Os parâmetros da cinética da degradação In vitro tiveram um comportamento diferenciado para as taxas de carboidratos não fibrosos (CNF) e carboidratos fibrosos (CF), o resíduo de mamão foi o único de cinco alimentos avaliados que mostrou um comportamento diferenciado, já que após 29 horas de incubação, os gases produzidos pelos carboidratos fibrosos superaram os gases produzidos pelos CNF, gerando fonte de energia secundária para crescimento dos microrganismos segundo AZEVÊDO et al. (2007a). A curva do total de gases produzidos está mostrado na figura 1 , evidenciando que o mamão foi o que apresentou maior produção $\mathrm{mL}$.

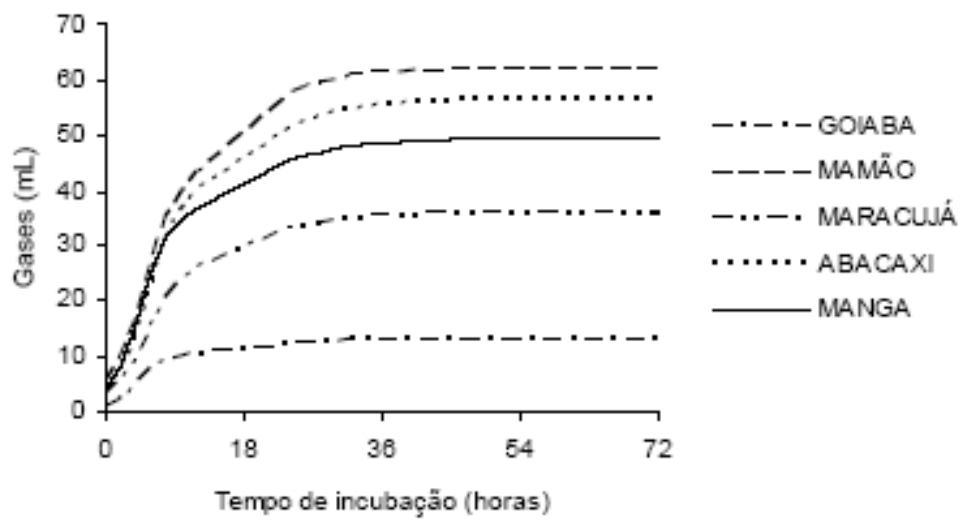

Figura 1. Produção de gás no tempo de incubação

Fonte: Azevedo et al., 2007a 
VALENTE, T.N.P. Utilização de resíduos de frutas na alimentação de ruminantes. PUBVET, Londrina, V. 5, N. 15, Ed. 162, Art. 1099, 2011.

\section{Avaliação de vários subprodutos de frutas}

LOUSADA JÚNIOR et al., (2005) estudaram subprodutos de abacaxi, acerola, goiaba, maracujá e melão, utilizando-se 20 ovinos machos castrados, com peso médio de $34,5 \mathrm{~kg}$. Sendo cinco tratamentos (subprodutos) e quatro repetições. A composição bromatológica está na tabela 7 .

Tabela 7. Composição bromatológica de diferentes subprodutos

\begin{tabular}{lccccc}
\hline \multirow{2}{*}{ Nutrientes } & \multicolumn{5}{c}{ Subprodutos } \\
\cline { 2 - 6 } & Abacaxi & Acerola & Goiaba & Maracujá & Melão \\
\hline MS (\%) & 84,7 & 85,1 & 86,3 & 83,3 & 84,6 \\
MO & 93,2 & 97,3 & 96,6 & 90,2 & 85,4 \\
PB & 8,4 & 10,5 & 8,5 & 12,4 & 17,3 \\
FDN & 71,4 & 71,9 & 73,5 & 56,2 & 59,1 \\
FDA & 30,7 & 54,7 & 54,7 & 49,0 & 49,2 \\
CEL & 25,9 & 35,1 & 37,2 & 39,3 & 32,6 \\
HEM & 40,7 & 17,2 & 18,8 & 10,3 & 9,9 \\
LIG & 5,3 & 20,1 & 18,5 & 9,5 & 16,6 \\
EE & 1,2 & 3,2 & 6,0 & 1,0 & 3,3 \\
CINZAS & 6,8 & 2,7 & 3,4 & 9,8 & 14,6 \\
NIDA1 & 16,3 & 26,5 & 21,0 & 20,0 & 14,8 \\
NIDN1 & 38,4 & 39,3 & 35,2 & 24,6 & 27,3 \\
\hline LOUSADA JÚNIOR et al., $2005(1=\%$ do $N$ total) & & &
\end{tabular}

Ao avaliar os consumos de matéria seca (CMS) LOUSADA JÚNIOR et al., (2005) perceberam semelhança no consumo dos subprodutos de goiaba, maracujá e melão, porém superiores ao CMS do subproduto de acerola (tabela 8). 
VALENTE, T.N.P. Utilização de resíduos de frutas na alimentação de ruminantes. PUBVET, Londrina, V. 5, N. 15, Ed. 162, Art. 1099, 2011.

Tabela 8. Consumo de MS para os subprodutos de abacaxi, acerola, goiaba maracujá e melão

\begin{tabular}{lcrc}
\hline Subproduto & \multicolumn{3}{c}{ CMS } \\
\cline { 2 - 4 } & $\mathrm{g} /$ animal/ dia & $\%$ PV\% & $\mathrm{g} / \mathrm{UTM}$ \\
\hline Abacaxi & $924,2 \mathrm{~b}$ & $2,7 \mathrm{~b}$ & $65,0 \mathrm{~b}$ \\
Acerola & $500,3 \mathrm{c}$ & $1,4 \mathrm{c}$ & $34,2 \mathrm{c}$ \\
Goiaba & $1527,4 \mathrm{a}$ & $4,4 \mathrm{a}$ & $106,8 \mathrm{a}$ \\
Maracujá & $1200,9 \mathrm{ab}$ & $3,5 \mathrm{ab}$ & $84,0 \mathrm{ab}$ \\
Melão & $1157,5 \mathrm{ab}$ & $3,5 \mathrm{ab}$ & $83,3 \mathrm{ab}$ \\
CV & 2,2 & 12,0 & 3,1 \\
\hline
\end{tabular}

LOUSADA JÚNIOR et al., 2005

Os maiores consumos de proteína bruta ( $\mathrm{CPB}$ ) foram observados com melão e maracujá sendo respectivamente 193,7 e 148,4 (g/animal/dia), enquanto acerola apresentou menor CPB de 55,5 (g/animal/dia). O maior consumo de fibra em detergente neutro (CFDN) pelos ovinos foi de 1126,4 (g/animal/dia) para o subproduto de goiaba e consequentemente refletiu em um maior consumo de fibra em detergente ácido (CFDA) de 842,9 (g/animal/dia). O resíduo de maracujá se destacou por apresentar maior coeficiente de digestibilidade aparente da matéria seca (DMS) de 60,0 e o pior resultado foi encontrado para o resíduo de acerola com 22,8 (DMS) e DMS para o subproduto goiaba foi de 30,8 mostrado na tabela 9.

Os subprodutos de abacaxi e maracujá caracterizaram-se por bom valor nutritivo, podendo ser utilizados na alimentação de ruminantes. Existem limitações na utilização dos subprodutos de goiaba na alimentação de ruminantes, necessitando maiores estudos, como a utilização de tratamentos químicos ou físicos que visem melhorar o valor nutritivo destes subprodutos LOUSADA JÚNIOR et al., (2005). 
VALENTE, T.N.P. Utilização de resíduos de frutas na alimentação de ruminantes. PUBVET, Londrina, V. 5, N. 15, Ed. 162, Art. 1099, 2011.

Tabela 9. Digestibilidade aparente para MS (DMS), PB (DPB), FDN (DFDN), MO (DMO) e nutrientes digestíveis totais NDT

\section{Nutriente}

Subproduto

\begin{tabular}{lllllll} 
& DMS & DPB & DFDN & DFDA & DMO & NDT \\
\hline Abacaxi & $47,5 \mathrm{~b}$ & $29,0 \mathrm{~b}$ & $50,8 \mathrm{a}$ & $51,0 \mathrm{~b}$ & $48,8 \mathrm{~b}$ & $45,6 \mathrm{~b}$ \\
Acerola & $22,8 \mathrm{c}$ & $33,2 \mathrm{~b}$ & $16,8 \mathrm{c}$ & $8,2 \mathrm{~d}$ & $30,1 \mathrm{c}$ & $32,2 \mathrm{~d}$ \\
Goiaba & $30,8 \mathrm{c}$ & $39,5 \mathrm{~b}$ & $17,7 \mathrm{c}$ & $13,0 \mathrm{~d}$ & $30,9 \mathrm{c}$ & $35,7 \mathrm{~d}$ \\
Maracujá & $60,0 \mathrm{a}$ & $54,4 \mathrm{a}$ & $56,2 \mathrm{a}$ & $65,4 \mathrm{a}$ & $58,2 \mathrm{a}$ & $52,9 \mathrm{a}$ \\
Melão & $47,7 \mathrm{~b}$ & $64,8 \mathrm{a}$ & $38,7 \mathrm{~b}$ & $38,7 \mathrm{c}$ & $45,9 \mathrm{~b}$ & $42,0 \mathrm{c}$ \\
CV & 9,5 & 13,7 & 11,8 & 11,2 & 7,9 & 7,7 \\
\hline
\end{tabular}

LOUSADA JÚNIOR et al., 2005

\section{Referências Bibliográficas}

AZEVÊDO, J. A. G. ; VALADARES FILHO, S. C. ; PINA, et al.. Composição química e parâmetros da cinética de produção de gases in vitro de resíduos de fruta para alimentação de ruminantes. In: XVII Congresso Brasileiro de Zootecnia e IX Congresso Internacional de Zootecnia, 2007, Londrina. XVII Congresso Brasileiro de Zootecnia e IX Congresso Internacional de Zootecnia. Londrina, 2007a.

AZEVÊDO, J. A. G. ; VALADARES FILHO, S. C. ; PINA, D. S. et al. . Consumo e digestibilidade total de resíduos de fruta para alimentação de ruminantes. In: XVII Congresso Brasileiro de Zootecnia e IX Congresso Internacional de Zootecnia, 2007, Londrina. XVII Congresso Brasileiro de Zootecnia e IX Congresso Internacional de Zootecnia. Londrina, 2007b.

CORREIA, M. X. C.; COSTA, R. G.; SILVA, J. H. V. et al. Utilização de resíduo agroindustrial de abacaxi desidratado em dietas para caprinos em crescimento: digestibilidade e desempenho.

Revista Brasileira de Zootecnia, v. 35, n. 4, p. 1822-1828, 2006.

DANTAS FILHO, L. A.; LOPES, J. B.; VASCONCELOS, V.R. et al. Inclusão de polpa de caju desidratada na alimentação de ovinos: desempenho, digestibilidade e balanço de nitrogênio.

Revista Brasileira de Zootecnia, v. 36, n.1, p. 147-154, 2007.

FAO. FAOSTAT Data Base. Disponível em: (www.fao.org ). Acesso em: 23 de maio de 2005.

FERREIRA, A. C. H.; NEIVA, J. N.; RODRIGUES, M. M. et al.Valor Nutritivo de Silagens de Capimelefante com Diferentes Níveis de Subprodutos da Indústria de suco de caju. Revista Brasileira de Zootecnia, v.33, n. 6, p.1380-1385, 2004. 
VALENTE, T.N.P. Utilização de resíduos de frutas na alimentação de ruminantes. PUBVET, Londrina, V. 5, N. 15, Ed. 162, Art. 1099, 2011.

FRANZOLIN, R.; SOARES W. V. B. Subprodutos da Indústria Alimentícia na Nutrição de Bovinos e Bubalinos. Anais... Seropédica. II Simpósio do Núcleo de Estudos em Bovinocultura p.99-112, 2005.

GONÇALVES, J. S., NEIVA, J. N., VIEIRA, N. F. et al. Valor Nutritivo de Silagens de Capim Elefante (Pennisetum purpureum Schum.) com Adição de Diferentes Níveis dos Subprodutos do Processamento de Acerola (Malpighia glabra L.) e de Goiaba (Psidium guajara L.). Revista Ciência Agronômica, vol. 35, n. 1, p.131-137, 2004.

LALLO, F. H.; PRADO, I. N.; NASCIMENTO, W. G. et al. Níveis de substituição da silagem de milho pela silagem de resíduo industrial de abacaxi sobre a degradabilidade ruminal em bovinos de corte. Revista Brasileira de Zootecnia, v. 32, n. 3, p. 719-726, 2003.

LOUSADA JÚNIOR, J. E., COSTA, J. M. C., NEIVA, J. N. M.et al. Consumo e Digestibilidade de Subprodutos do Processamento de Frutas em Ovinos. Revista Brasileira de Zootecnia, v. 34, n.2, p.659-669, 2005.

LOUSADA JÚNIOR, J. E., COSTA, J. M. C., NEIVA, J. N. M. et al. Caracterização Físico-química de Subprodutos Obtidos do Processamento de Frutas Tropicais Visando seu Aproveitamento na Alimentação Animal. Revista Ciência Agronômica, v. 37, n.1, p.70-76, 2006.

NEIVA JÚNIOR, A. P.; SILVA FILHO, J. C.; VAN TIESENHAUSEN, I., M. E. V. et al. Efeito de diferentes aditivos sobre os teores de proteína bruta, extrato etéreo e digestibilidade da silagem de maracujá. Ciência e Agrotecnologia, v. 31, n. 3, p. 871-875, 2007.

NEIVA, J. N., NUNES, F. C. S., CÂNDIDO, B. et al. Valor Nutritivo de Silagens de Capim-elefante Enriquecidas com Subproduto do Processamento do Maracujá. Revista Brasileira de Zootecnia, v. 35, n.4 p. $1845-1851,2006$.

PRADO, I. N.; LALLO, F. H.; ZEOULA, L. M. et al. Níveis de substituição da silagem de milho pela silagem de resíduo industrial de abacaxi sobre o desempenho de bovinos confinados. Revista Brasileira de Zootecnia, v. 32, n. 3, p. 737-744, 2003.

REIS, J.; PAIVA, P.C.A.; Von TIESENHAUSEN, I, M. E. V. et al. Composição química, consumo voluntário e digestibilidade de silagens de resíduos do fruto de maracujá (Passiflora edulis Sims f. flavicarpa) e de capim-elefante (Pennisetum purpureum Schum) cv. Cameroon e suas combinações. Ciência e Agrotecnologia, v.24, n.1, p.213-224, 2000.

RODRIGUES, M. M.; NEIVA, J. N. M.; VASCONCELOS, V. R. et al. Utilização do farelo de castanha de caju na terminação de ovinos em confinamento. Revista Brasileira de Zootecnia, v. 32, n.1, p. 240-248, 2003. 